\title{
Hydrogen-Bonding Linkers Yield a Large-Pore, Non-Catenated, Metal-Organic Framework with pcu Topology
}

\author{
Mohammad S. Yazdanparast ${ }^{1}$, Victor W. Day ${ }^{2}$ and Tendai Gadzikwa ${ }^{1, *(D)}$ \\ 1 Department of Chemistry, Kansas State University, Manhattan, KS 66506, USA; yazdanparast@ksu.edu \\ 2 Department of Chemistry, University of Kansas, Lawrence, KS 66045, USA; vwday@ku.edu \\ * Correspondence: gadzikwa@ksu.edu
}

Academic Editors: Victoria Samanidou, Eleni Deliyanni and Liudmil Antonov

Received: 22 December 2019; Accepted: 3 February 2020; Published: 6 February 2020

check for updates

\begin{abstract}
Pillared paddle-wheel-based metal-organic framework (MOF) materials are an attractive target as they offer a reliable method for constructing well-defined, multifunctional materials. A drawback of these materials, which has limited their application, is their tendency to form catenated frameworks with little accessible volume. To eliminate this disadvantage, it is necessary to investigate strategies for constructing non-catenated pillared paddle-wheel MOFs. Hydrogen-bonding substituents on linkers have been postulated to prevent catenation in certain frameworks and, in this work, we present a new MOF to further bolster this theory. Using 2,2' -diamino-[1,1'-biphenyl]-4,4'-dicarboxylic acid, BPDC-( $\left.\mathrm{NH}_{2}\right)_{2}$, linkers and dipyridyl glycol, DPG, pillars, we assembled a MOF with pcu topology. The new material is non-catenated, exhibiting large accessible pores and low density. To the best of our knowledge, this material constitutes the pcu framework with the largest pore volume and lowest density. We attribute the lack of catenation to the presence of H-bonding substituents on both linkers.
\end{abstract}

Keywords: metal-organic framework; mixed-ligand; pillared; paddle-wheel; non-catenated; large-pore; hydrogen-bonding

\section{Introduction}

While there are a variety of ways to assemble well-defined, multifunctional metal-organic framework (MOF) materials [1], the construction of mixed-linker, pillared paddle-wheel MOFs is the most efficacious (Figure 1) [2]. Their assembly provides a reliable strategy for introducing two different organic linkers into an MOF, allowing for the chemical pore environment to be tuned with high fidelity [3]. Despite the advantages that they offer, following their first introduction, pillared paddle-wheel frameworks have received much less attention than their potential would warrant. This is owing to two limitations: the $\mathrm{M}^{2+}$-paddle-wheel secondary building unit (SBU, Figure 1 ) is not as chemically stable as many other clusters [4] and, due to the small size of the SBU, the frameworks are prone to catenation. Though the challenges of relatively poor stability and low porosity due to catenation can be addressed post MOF assembly, via transmetallation [5-7] and solvent-assisted linker exchange (SALE) [8,9], the de novo synthesis of such materials would be preferable. Thus, there is a need to investigate strategies to incorporate preferred cations and to prevent catenation in the solvothermal synthesis of pillared paddle-wheel MOFs. In this report, we present an unusual, non-catenated, large pore, pillared paddle-wheel MOF, providing an additional datapoint to support current postulation on the factors that may influence catenation in these frameworks. 

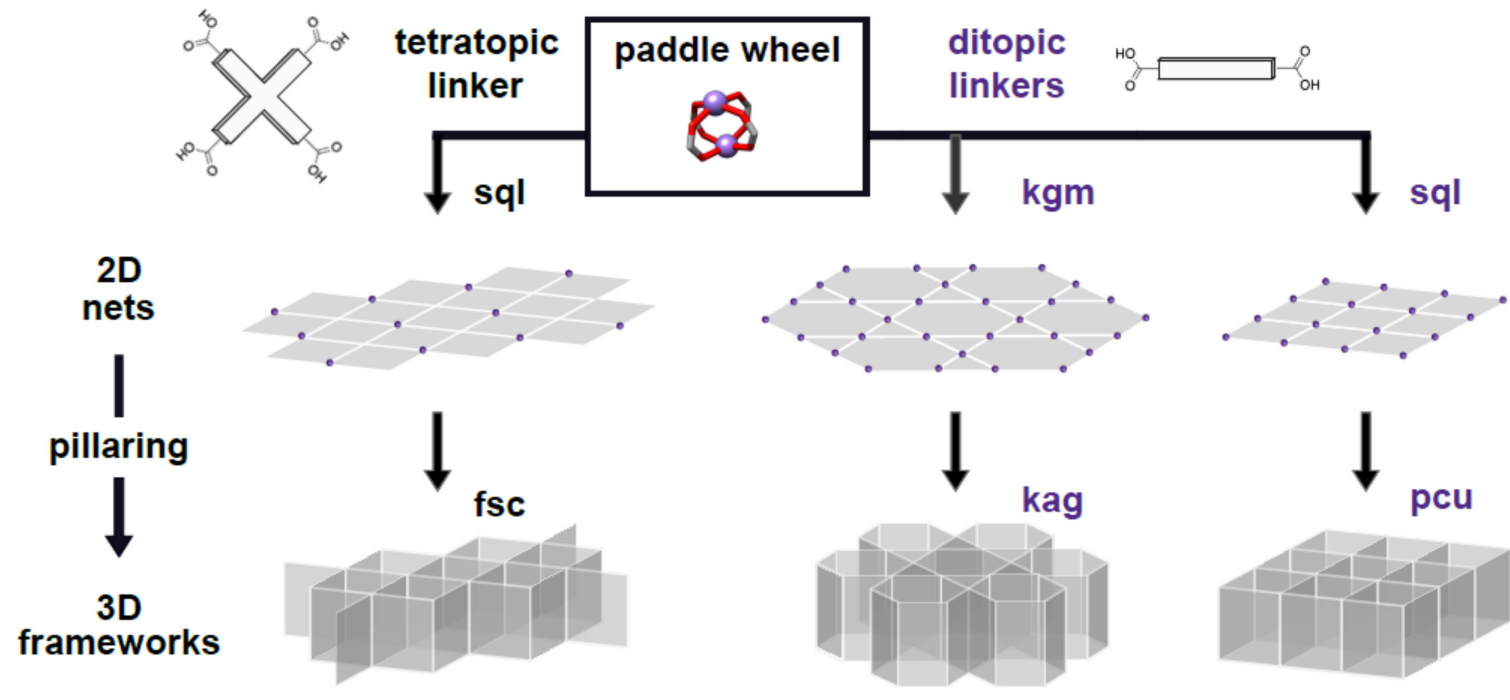

Figure 1. Schematic representation of the possible topologies for pillared, paddle-wheel metal organic frameworks (MOFs). The 2D nets are pillared to form 3D MOFs. MOFs of pcu and fsc are derived from sql nets, and kag MOFs are derived from kgm nets.

A major focus of our group is the uniform multifunctionalization of MOFs. To this end, we have been synthesizing pillared paddle-wheel MOFs where the two different linkers bear reactive groups that can be addressed independently post MOF assembly [10,11]. In this work, we specifically target non-catenated frameworks that can accommodate additional functionality. Specifically, we sought pillared frameworks with the kag topology as, unlike the more common pcu-based structures, they are non-catenated with large pores (Figure 1). For our ligands, we employed dipryridyl glycol, DPG, together with either 2-amino-1,4-benzenediacarboxylic acid $\left(\mathrm{BDC}^{-\mathrm{NH}_{2}}\right.$ or 2-azido-1,4-benzenediacarboxylic acid $\left(B D C-N_{3}\right)$. With the intent of constructing a symmetric version of such MOFs, we then attempted the construction of a kag MOF composed of $\mathrm{Zn}^{2+}$, 2,2'-diamino-[1,1'-biphenyl]-4,4'-dicarboxylic acid, BPDC-( $\left.\mathrm{NH}_{2}\right)_{2}$, and DPG. Gratifyingly, we obtained a non-catenated structure. Unexpectedly, however, we found the structure to have the pcu topology.

\section{Results}

Combining BPDC-( $\left.\mathrm{NH}_{2}\right)_{2}$, and DPG under the low-temperature nucleation conditions generally employed to obtain kag MOFs [12,13], we obtained pale-yellow, block-like crystals that were suitable for single-crystal X-ray analysis. Following refinement of the diffraction data, we found that we had obtained a pcu framework, KSU-100, that is non-catenated (Figure 2b).

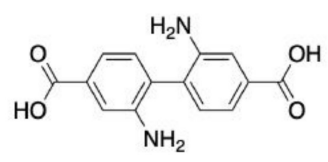

BPDC- $\left(\mathrm{NH}_{2}\right)_{2}$<smiles>OC(c1ccncc1)[C@@H](O)c1ccncc1</smiles>

DPG

(a)

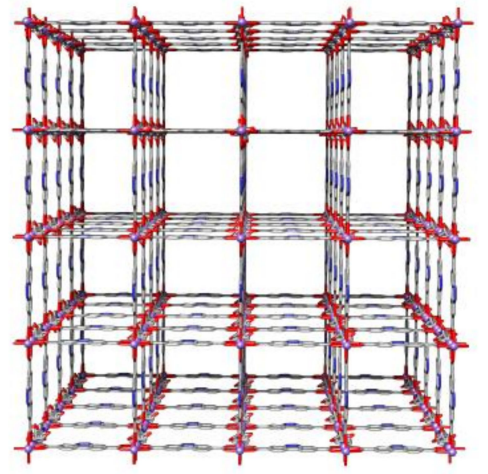

(b)

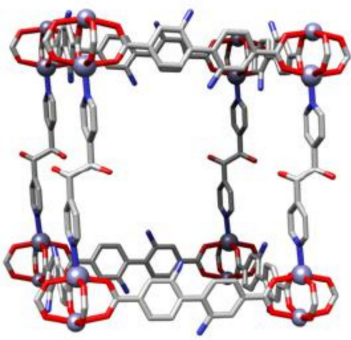

(c)

Figure 2. (a) MOF linkers; (b) KSU-100 viewed down the c-axis; (c) Network unit of KSU-100. 
Crystal data for C10H7N1.50O2.50Zn0.50 (M = $220.86 \mathrm{~g} / \mathrm{mol})$ : monoclinic, space group P4, $\mathrm{a}=15.1970(5) \AA, \mathrm{b}=15.1970(5) \AA, \mathrm{c}=16.2095(5) \AA, \mathrm{V}=3743.6(3) \AA^{3}, \mathrm{Z}=4, \mathrm{~T}=200(2) \mathrm{K}$, $\mu(\mathrm{CuK} \alpha)=0.542 \mathrm{~mm}^{-1}, \mathrm{D}_{\text {calc }}=0.392 \mathrm{~g} / \mathrm{cm}^{3}, 33,836$ reflections measured $\left(2.908^{\circ} \leq 2 \Theta \leq 68.403^{\circ}\right)$, 6586 unique $\left(\mathrm{R}_{\text {int }}=0.0490\right)$ which were used in all calculations. The final R1 was $0.1026(\mathrm{I}>2 \sigma(\mathrm{I}))$ and wR2 was 0.2860 (all data).

The new MOF, KSU-100, has the BPDC-( $\left(\mathrm{NH}_{2}\right)_{2}$ linkers connected by $\mathrm{Zn}$ paddle-wheel clusters, defining the $x y$-plane in a sql net. This $2 \mathrm{D}$ net is then pillared together by the DPG ligand to form a pcu framework with large pore dimensions of $11 \AA \times 11 \AA \times 9 \AA$, and a low calculated density of $0.392 \mathrm{~g} / \mathrm{cm}^{3}$. Powder X-ray diffraction (PXRD) of bulk samples of single-crystals of the material confirmed the purity of the structure (Figure 3a, and Figure S1 in Supporting Information for the indexed pattern). Note that large crystals were used instead of powders, as the powders lost solvent rapidly and did not produce adequate diffraction patterns. Thermogravimetric analysis (TGA) indicates that KSU-100 loses $60 \%$ of its weight as solvent. Such a significant loss confirms that the material has a large solvent-accessible volume and supports that the bulk material is indeed non-catenated (Figure 3b).

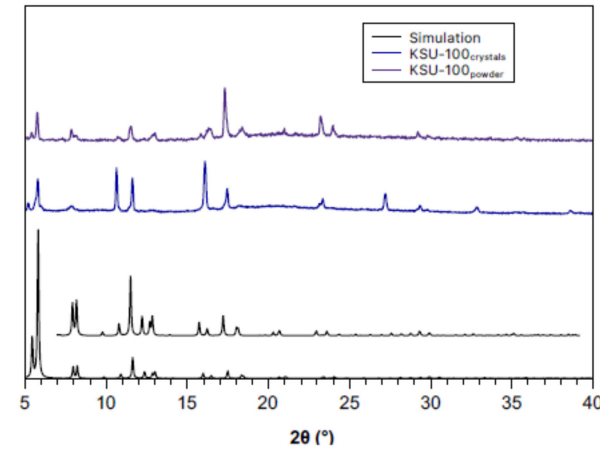

(a)

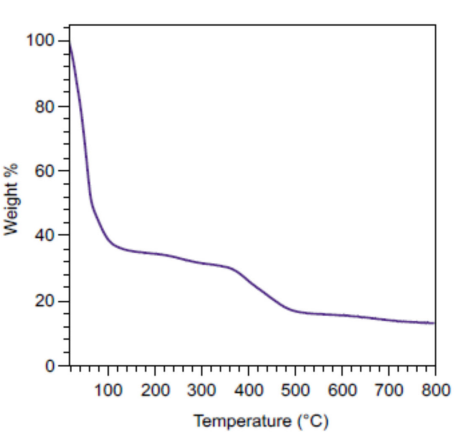

(b)

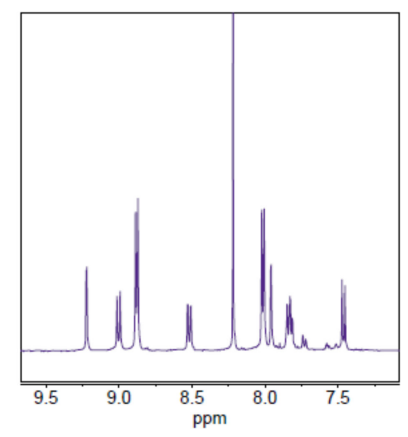

(c)

Figure 3. Characterization of KSU-100: (a) Powder diffraction patterns of the simulated pattern based on the single-crystal data, single crystals, and powder of KSU-100. The insert is a magnification of the smaller peaks of the simulation; (b) Thermogravimetric analysis (TGA) trace of the MOF solvated with DMF; (c) ${ }^{1} \mathrm{H}-\mathrm{NMR}$ of KSU-100 digested in a TFA- $d_{1}$ and $d_{6}$-DMSO mixture.

To confirm the composition of the material, we performed proton nuclear magnetic resonance $\left({ }^{1} \mathrm{H}-\mathrm{NMR}\right)$ spectroscopy of KSU-100 digested in a mixture of deuterated trifluoroacetic acid, TFA- $d_{1}$, and deuterated dimethylsulfoxide, DMSO- $d_{6}$ (Figure $3 c$ ). Integration of the ligand peaks (Figure S2) indicates a BPDC-( $\left.\mathrm{NH}_{2}\right)_{2}$ :DPG ratio of 2:1, as is to be expected for a pillared paddle-wheel MOF. Note that there are two sets of protons corresponding to BPDC-( $\left.\mathrm{NH}_{2}\right)_{2}$. Literature precedence indicates that the ligand undergoes multiple transformations in the presence of metal cations and strong acid [14]. We found that using TFA as the digestion acid reduced the number of complexes formed, allowing us to identify and integrate the peaks.

\section{Discussion}

Pillared paddle-wheel MOFs comprise $\mathrm{M}^{2+}$-acetate centers connected by multicarboxylate linkers to form two possible two-dimensional (2D) nets: sql and kgm (Figure 1) [15]. When the paddle-wheel nets are pillared together by ditopic linkers they form 3D frameworks. Of the three pillared paddle-wheel MOF topologies that can be formed, only the kag topology, formed from the kgm net, has consistently been non-catenated. While low temperature nucleation has been suggested as a method for generating these wide-channel MOFs [13], this topology is relatively rare, with a handful of reports in the last several years $[10-13,16,17]$. The more common sql net, formed by di- and tetratopic dicarboxylate ligands, is pillared to form the pcu and fsc nets, respectively [15].

Of the sql-based structures, the fsc frameworks constructed with tetracarboxy linkers have thus far provided the most reliable route to large-pore, non-catenated, pillared paddle-wheel MOFs. 
The topology has been primarily reported with the tetrakis(4-carboxyphenyl)porphine (TCPP) [18-21] and tetrakis(4-carboxyphenyl)benzene, TCPB [22]. The TCPP-based MOFs are all non-catenated, but the TCPB linker produces a net with openings that are large enough to accommodate an additional framework, resulting in frequent catenation [22,23]. Catenation has been prevented by the presence of blocking functional groups on the tetracarboxylate [8], or by using dipyridyl pillars that are bulky or have bulky substituents [24-26]. The exception to this trend is DO-MOF, a structure where the dipyridyl linker is the seemingly inobtrusive dipryridyl glycol, DPG [27].

The pcu topology is generally catenated, unless the MOF is composed of short dicarboxylate linkers or short pillars. The use of short linkers results in frameworks that lack the space to accommodate additional frameworks, thus the lack of catenation comes at the expense of larger pore volumes [28]. The single exception is a non-catenated pcu framework, BMOF-1-bpdc- $\mathrm{NO}_{2}$, composed of bipyridine (BIPY) pillars, and a long 4,4'-biphenyl dicarboxylate (BPDC) linker bearing a nitro substituent [29]. For the TCPB-based MOF, it has been speculated that the hydrogen-bonding capability of the DPG linker is responsible for preventing catenation in DO-MOF [8]. That result, combined with the existence of a large-pore, non-catenated pcn framework that is decorated with H-bond accepting nitro groups, prompts the question of whether catenation can be influenced by substituents that participate in hydrogen bonding. The new MOF, KSU-100, lends credence to this theory by presenting another large-pore, non-catenated pcu MOF, constructed using linkers bearing H-bonding substituents.

While we cannot identify the limits of pore dimensions for the construction of pcu type MOFs that are non-catenated, it is extraordinary that a pcu MOF with a BPDC-based linker is non-catenated. For the small dicarboxylate linker benzene dicarboxylate (BDC), catenated pcu MOFs are formed when sufficiently long pillars are used, including the relatively short BIPY [30-35]. The same is true for the slightly longer naphthalene dicarboxylate (NDC) linker [36], which still forms catenated structures when the dipyridyl liker has bulky (trimethylsilyl)ethynyl substituents [37]. Even the small, 4-carbon fumarate (FMA) linker forms a catenated pcu MOF with the one-ring pyrazine (PYZ) pillar [38]. Given the prevalence of catenation even with short dicarboxylates, it is expected that pcu structures of the longer BPDC linker should be catenated.

There is only one report of a non-catenated pcu structure of BPDC and a non-hydrogen-bonding pillar, and it is one where the co-linker is the short and bulky DABCO [39]. All other pcu structures of BPDC are, at minimum, 2-fold catenated, even when the dipyridyl linker has bulky substituents. Sterically demanding substituents on pillars include anthracene [40] and a 24-member interlocking ring [41], and these pillars have formed 2-fold catenated pcu MOFs with BPDC. A pillar containing the bulky triptycene moiety results in a 4-fold catenated MOF with BPDC [35]. Given these examples, and the lack of catenation in KSU-100 and in BMOF-1-bpdc- $\mathbf{N O}_{2}$, it is reasonable to assume that it is the electronic nature of the substituents, not their size, that prevents catenation.

Hupp and co-workers [23], and others [42], have suggested that H-bonding between linker substituents and solvent molecules can increase the steric requirements of linkers, preventing catenation. It should be noted that that there is a pcu structure that is 3-fold catenated despite having DPG as a pillar [43]. The dicarboxylate ligand in this case is azobenzene-4,4'-dicarboxylic acid, a linker that is only $\sim 2 \AA$ longer than BPDC. This result suggests that this may be where the threshold void volume exists, i.e., where the H-bonding capability of DPG is no longer sufficient to prevent catenation. In KSU-100, the BPDC- $\left(\mathrm{NH}_{2}\right)_{2}$ linkers and the DPG pillar each have two H-bonding substituents, resulting in a dense concentration of $\mathrm{H}$-bond donors and acceptors in the framework. Such an environment is conducive to the creation of a dense network of $\mathrm{H}$-bonded solvent molecules in the pores. We presume that this is why catenation does not take place despite the significant void volume.

\section{Materials and Methods}

All chemicals were used as received from commercial sources unless otherwise noted. Meso- $\alpha, \beta$-di(4-pyridyl) glycol (DPG) was purchased from TCI America (Portland, OR, USA). $\mathrm{N}, \mathrm{N}$-dimethylformamide (DMF) was purchased from Fisher Scientific (Pittsburgh, PA, USA), and 
zinc nitrate hexahydrate from Strem Chemicals (Newburyport, MA, USA). Dimethyl sulfoxide- $\mathrm{d}_{6}$ $\left(d_{6}\right.$-DMSO, 99.9 atom $\left.\% \mathrm{D}\right)$ was purchased from Cambridge Isotope Laboratories (Tewksbury, MA, USA), while trifluoroacetic acid-d (TFA- $d 199.5$ atom \% D) was purchased from Sigma-Aldrich (St Louis, MO, USA). 2,2'-Diaminobiphenyl-4,4'-dicarboxylic acid (BPDC- $\left.\left(\mathrm{NH}_{2}\right)_{2}\right)$ was synthesized following a literature procedure [14].

Synthesis of KSU-100: in a $500 \mathrm{~mL}$ round-bottom flask, $\mathrm{Zn}\left(\mathrm{NO}_{3}\right)_{2} \cdot 6 \mathrm{H}_{2} \mathrm{O}(400.0 \mathrm{mg}, 0143 \mathrm{mmol})$ and DPG (160.0 mg, $0.74 \mathrm{mmol})$ were added to $250 \mathrm{~mL}$ DMF and stirred at RT for $30 \mathrm{~min}$. BPDC-( $\left(\mathrm{NH}_{2}\right)_{2}$ ( $400.0 \mathrm{mg}, 0.147 \mathrm{mmol}$ ) was added to the mixture and left to stir at room temperature for $10 \mathrm{~min}$. The flask was then incubated at $60^{\circ} \mathrm{C}$. After $14 \mathrm{~h}$, the flask was removed from the heating block and left at room temperature for $30 \mathrm{~h}$. Pale yellow crystals ( $300 \mathrm{mg}, 30 \%$ yield) of the product were collected by filtration and stored in fresh DMF.

Details of single-crystal X-ray analysis are available in the Supporting Information. CCDC 1972127 contains the supplementary crystallographic data for this paper. These data are provided free of charge by the Cambridge Crystallographic Data Centre.

Powder X-ray diffraction (PXRD) patterns were recorded on a Bruker AXS D8 Advance Phaser diffractometer (Bruker AXS GmbH, Karlsruhe, Germany) with $\mathrm{Cu} K \alpha$ radiation $(\lambda=1.5418 \AA$ ) over a range of $5^{\circ}<2 \theta<40^{\circ}$ in $0.02^{\circ}$ steps, with a $0.5 \mathrm{~s}$ counting time per step. Samples were collected from the bottom of the reaction vial as a thick suspension in DMF and spread on a Si-Einkristalle plate immediately before PXRD measurements.

Thermogravimetric analysis (TGA) was performed on a TGA-Q50 (TA Instruments, New Castle, DE, USA) interfaced with a PC using TA Universal Analysis software. Samples were heated at a rate of $10^{\circ} \mathrm{C} / \mathrm{min}$ under a nitrogen atmosphere. All samples were extensively solvent-exchanged with fresh DMF prior to analysis.

The proton NMR spectrum of KSU-100 was recorded on a Bruker Avance NEO spectrometer (400 MHz for ${ }^{1} \mathrm{H}$, Bruker BioSpin, Billerica, MA, USA). NMR chemical shifts are reported in ppm against a residual solvent resonance as the internal standard $\left(\delta\left(d_{6}-\mathrm{DMSO}\right)=2.5 \mathrm{ppm}\right)$. In a typical analysis, MOF materials were washed thoroughly with DMF. The sample was isolated and dried under vacuum at $60^{\circ} \mathrm{C}$ for minimum of $2 \mathrm{~h}$. The dry MOF sample $(\sim 5 \mathrm{mg})$ was digested in a mixture of 0.400 $\mathrm{mL} d_{6}$-DMSO $(0.1 \mathrm{~mL})$ and TFA- $d_{1}(0.100 \mathrm{~mL})$ and then transferred into an NMR tube.

Fourier-transform infrared spectroscopy of KSU-100 was performed on an Agilent Cary 630 spectrometer (Agilent Technologies, Santa Clara, CA, USA). The MOF sample ( 1 mg) was combined with five mass equivalents $(\sim 5 \mathrm{mg})$ of $\mathrm{KBr}$ and ground together to a fine powder.

\section{Conclusions}

In our own work of covalently functionalizing MOFs post-synthesis, it has been crucial to synthesize non-catenated frameworks that have enough space to accommodate additional functionality. Doubtless, accessible pore volume is necessary for a variety of other MOF applications. In this work, we have provided an additional datapoint to support the assertion that hydrogen-bonding substituents on linkers can prevent catenation in pillared, paddle-wheel MOFs. With this information, MOF chemists who are interested in the well-defined multifunctionality of these materials now have a potential avenue for constructing non-catenated variants of these pillared frameworks.

Supplementary Materials: The following are available online, Crystallographic Information File (CIF) for KSU-100 and Supporting Information.

Author Contributions: Conceptualization, T.G.; investigation, M.S.Y.; crystallography, V.W.D.; writing-review and editing, M.S.Y. and T.G.; funding acquisition, T.G. All authors have read and agreed to the published version of the manuscript.

Funding: This study was supported by a National Science Foundation grant, CHE-1800517, and NSF-MRI grants, CHE-0923449 to the University of Kansas to purchase the X-ray diffractometer and software used in this study, and CHE-1826982 to Kansas State University for the NMR spectrometer used in this study. The authors also acknowledge the Aakeröy Lab at KState for use of their TGA. 
Acknowledgments: We acknowledge the Aakeröy lab at KState for use of their TGA instrument, and Kanchana P. Samarakoon for assistance with NMR studies.

Conflicts of Interest: The authors declare no conflict of interest.

\section{References}

1. Qin, J.-S.; Yuan, S.; Wang, Q.; Alsalme, A.; Zhou, H.-C. Mixed-linker strategy for the construction of multifunctional metal-organic frameworks. J. Mater. Chem. A 2017, 5, 4280-4291. [CrossRef]

2. Hashemi, L.; Morsali, A. Pillared Metal-Organic Frameworks: Properties and Applications; John Wiley \& Sons: Hoboken, NJ, USA, 2019; ISBN 978-1-119-46024-4.

3. ZareKarizi, F.; Joharian, M.; Morsali, A. Pillar-layered MOFs: Functionality, interpenetration, flexibility and applications. J. Mater. Chem. A 2018, 6, 19288-19329. [CrossRef]

4. Burtch, N.C.; Walton, K.S. Modulating adsorption and stability properties in pillared metal-organic frameworks: A model system for understanding ligand effects. Acc. Chem. Res. 2015, 48, 2850-2857. [CrossRef] [PubMed]

5. Lalonde, M.; Bury, W.; Karagiaridi, O.; Brown, Z.; Hupp, J.T.; Farha, O.K. Transmetalation: Routes to metal exchange within metal-organic frameworks. J. Mater. Chem. A 2013, 1, 5453-5468. [CrossRef]

6. Karagiaridi, O.; Bury, W.; Fairen-Jimenez, D.; Wilmer, C.E.; Sarjeant, A.A.; Hupp, J.T.; Farha, O.K. Enhanced gas sorption properties and unique behavior toward liquid water in a pillared-paddlewheel metal-organic framework transmetalated with $\mathrm{Ni}(\mathrm{II})$. Inorg. Chem. 2014, 53, 10432-10436. [CrossRef]

7. Xu, Y.; Howarth, A.J.; Islamoglu, T.; da Silva, C.T.; Hupp, J.T.; Farha, O.K. Combining solvent-assisted linker exchange and transmetallation strategies to obtain a new non-catenated nickel (II) pillared-paddlewheel MOF. Inorg. Chem. Commun. 2016, 67, 60-63. [CrossRef]

8. Farha, O.K.; Malliakas, C.D.; Kanatzidis, M.G.; Hupp, J.T. Control over catenation in metal-organic frameworks via rational design of the organic building block. J. Am. Chem. Soc. 2010, 132, 950-952. [CrossRef]

9. Karagiaridi, O.; Bury, W.; Tylianakis, E.; Sarjeant, A.A.; Hupp, J.T.; Farha, O.K. Opening metal-organic frameworks Vol. 2: Inserting longer pillars into pillared-paddlewheel structures through solvent-assisted linker exchange. Chem. Mater. 2013, 25, 3499-3503. [CrossRef]

10. Samarakoon, K.P.; Satterfield, C.S.; McCoy, M.C.; Pivaral-Urbina, D.A.; Islamoglu, T.; Day, V.W.; Gadzikwa, T. Uniform, binary functionalization of a metal-organic framework material. Inorg. Chem. 2019, 58, 8906-8909. [CrossRef]

11. Samarakoon, K.; Yazdanparast, M.; Day, V.W.; Gadzikwa, T. Uniform and simultaneous orthogonal functionalization of a metal-organic framework material. ChemRxiv 2020. [CrossRef]

12. Kondo, M.; Takashima, Y.; Seo, J.; Kitagawa, S.; Furukawa, S. Control over the nucleation process determines the framework topology of porous coordination polymers. CrystEngComm 2010, 12, 2350-2353. [CrossRef]

13. Zhou, K.; Chaemchuen, S.; Wu, Z.; Verpoort, F. Rapid room temperature synthesis forming pillared metal-organic frameworks with Kagomé net topology. Microporous Mesoporous Mater. 2017, 239, $28-33$. [CrossRef]

14. Ko, N.; Hong, J.; Sung, S.; Cordova, K.E.; Park, H.J.; Yang, J.K.; Kim, J. A significant enhancement of water vapour uptake at low pressure by amine-functionalization of UiO-67. Dalton Trans. 2015, 44, 2047-2051. [CrossRef]

15. Guillerm, V.; Kim, D.; Eubank, J.F.; Luebke, R.; Liu, X.; Adil, K.; Soo Lah, M.; Eddaoudi, M. A supermolecular building approach for the design and construction of metal-organic frameworks. Chem. Soc. Rev. 2014, 43, 6141-6172. [CrossRef]

16. Chun, H.; Moon, J. Discovery, synthesis, and characterization of an isomeric coordination polymer with pillared kagome net topology. Inorg. Chem. 2007, 46, 4371-4373. [CrossRef]

17. Hungerford, J.; Walton, K.S. Room-Temperature synthesis of metal-organic framework isomers in the tetragonal and kagome crystal structure. Inorg. Chem. 2019, 58, 7690-7697. [CrossRef] [PubMed]

18. Barron, P.M.; Son, H.-T.; Hu, C.; Choe, W. Highly tunable heterometallic frameworks constructed from paddle-wheel units and metalloporphyrins. Cryst. Growth Des. 2009, 9, 1960-1965. [CrossRef] 
19. Lee, C.Y.; Farha, O.K.; Hong, B.J.; Sarjeant, A.A.; Nguyen, S.T.; Hupp, J.T. Light-Harvesting metal-organic frameworks (MOFs): Efficient strut-to-strut energy transfer in bodipy and porphyrin-based MOFs. J. Am. Chem. Soc. 2011, 133, 15858-15861. [CrossRef]

20. Park, J.; Feng, D.; Yuan, S.; Zhou, H.-C. Photochromic metal-organic frameworks: Reversible control of singlet oxygen generation. Angew. Chem. Int. Ed. 2015, 54, 430-435. [CrossRef]

21. Danowski, W.; van Leeuwen, T.; Abdolahzadeh, S.; Roke, D.; Browne, W.R.; Wezenberg, S.J.; Feringa, B.L. Unidirectional rotary motion in a metal-organic framework. Nat. Nanotechnol. 2019, 14, 488-494. [CrossRef]

22. Mulfort, K.L.; Farha, O.K.; Malliakas, C.D.; Kanatzidis, M.G.; Hupp, J.T. An Interpenetrated Framework Material with Hysteretic CO2 Uptake. Chem. Eur. J. 2010, 16, 276-281. [CrossRef] [PubMed]

23. Bury, W.; Fairen-Jimenez, D.; Lalonde, M.B.; Snurr, R.Q.; Farha, O.K.; Hupp, J.T. Control over catenation in pillared paddlewheel metal-organic framework materials via solvent-assisted linker exchange. Chem. Mater. 2013, 25, 739-744. [CrossRef]

24. Gadzikwa, T.; Farha, O.K.; Malliakas, C.D.; Kanatzidis, M.G.; Hupp, J.T.; Nguyen, S.T. Selective bifunctional modification of a non-catenated metal-organic framework material via "Click" chemistry. J. Am. Chem. Soc. 2009, 131, 13613-13615. [CrossRef] [PubMed]

25. Shultz, A.M.; Farha, O.K.; Hupp, J.T.; Nguyen, S.T. A catalytically active, permanently microporous MOF with metalloporphyrin struts. J. Am. Chem. Soc. 2009, 131, 4204-4205. [CrossRef] [PubMed]

26. Shultz, A.M.; Farha, O.K.; Adhikari, D.; Sarjeant, A.A.; Hupp, J.T.; Nguyen, S.T. Selective Surface and Near-Surface Modification of a Noncatenated, Catalytically Active Metal-Organic Framework Material Based on Mn(salen) Struts. Inorg. Chem. 2011, 50, 3174-3176. [CrossRef]

27. Mulfort, K.L.; Farha, O.K.; Stern, C.L.; Sarjeant, A.A.; Hupp, J.T. Post-Synthesis alkoxide formation within metal-organic framework materials: A strategy for incorporating highly coordinatively unsaturated metal ions. J. Am. Chem. Soc. 2009, 131, 3866-3868. [CrossRef]

28. Ma, B.-Q.; Mulfort, K.L.; Hupp, J.T. Microporous pillared paddle-wheel frameworks based on mixed-ligand coordination of zinc ions. Inorg. Chem. 2005, 44, 4912-4914. [CrossRef]

29. Dau, P.V.; Cohen, S.M. The influence of nitro groups on the topology and gas sorption property of extended Zn(II)-paddlewheel MOFs. CrystEngComm 2013, 15, 9304-9307. [CrossRef]

30. Chen, B.; Liang, C.; Yang, J.; Contreras, D.S.; Clancy, Y.L.; Lobkovsky, E.B.; Yaghi, O.M.; Dai, S. A microporous metal-organic framework for gas-chromatographic separation of alkanes. Angew. Chem. Int. Ed. 2006, 45, 1390-1393. [CrossRef]

31. Du, M.; Zhang, Z.-H.; Wang, X.-G.; Tang, L.-F.; Zhao, X.-J. Structural modulation of polythreading and interpenetrating coordination networks with an elongated dipyridyl building block and various anionic co-ligands. CrystEngComm 2008, 10, 1855-1865. [CrossRef]

32. Seo, J.; Bonneau, C.; Matsuda, R.; Takata, M.; Kitagawa, S. Soft secondary building unit: Dynamic bond rearrangement on multinuclear core of porous coordination polymers in gas media. J. Am. Chem. Soc. 2011, 133, 9005-9013. [CrossRef] [PubMed]

33. Liu, X.-M.; Xie, L.-H.; Lin, J.-B.; Lin, R.-B.; Zhang, J.-P.; Chen, X.-M. Flexible porous coordination polymers constructed from 1,2-bis(4-pyridyl)hydrazinevia solvothermal in situreduction of 4,4'-azopyridine. Dalton Trans. 2011, 40, 8549-8554. [CrossRef] [PubMed]

34. Safarifard, V.; Morsali, A. Influence of an amine group on the highly efficient reversible adsorption of iodine in two novel isoreticular interpenetrated pillared-layer microporous metal-organic frameworks. CrystEngComm 2014, 16, 8660-8663. [CrossRef]

35. Jiang, X.; Duan, H.-B.; Khan, S.I.; Garcia-Garibay, M.A. Diffusion-Controlled rotation of triptycene in a metal-organic framework (MOF) sheds light on the viscosity of mof-confined solvent. ACS Cent. Sci. 2016, 2, 608-613. [CrossRef]

36. Chun, H.; Dybtsev, D.N.; Kim, H.; Kim, K. Synthesis, X-ray Crystal Structures, and Gas Sorption Properties of Pillared Square Grid Nets Based on Paddle-Wheel Motifs: Implications for Hydrogen Storage in Porous Materials. Chem. Eur. J. 2005, 11, 3521-3529. [CrossRef]

37. Gadzikwa, T.; Lu, G.; Stern, C.L.; Wilson, S.R.; Hupp, J.T.; Nguyen, S.T. Covalent surface modification of a metal-organic framework: Selective surface engineering via CuI-catalyzed Huisgen cycloaddition. Chem. Commun. 2008, 5493-5495. [CrossRef] 
38. Chen, B.; Ma, S.; Zapata, F.; Fronczek, F.R.; Lobkovsky, E.B.; Zhou, H.-C. Rationally designed micropores within a metal-organic framework for selective sorption of gas molecules. Inorg. Chem. 2007, 46, 1233-1236. [CrossRef]

39. Dau, P.V.; Kim, M.; Garibay, S.J.; Münch, F.H.L.; Moore, C.E.; Cohen, S.M. Single-Atom ligand changes affect breathing in an extended metal-organic framework. Inorg. Chem. 2012, 51, 5671-5676. [CrossRef]

40. Qi, Y.; Xu, H.; Li, X.; Tu, B.; Pang, Q.; Lin, X.; Ning, E.; Li, Q. Structure transformation of a luminescent pillared-layer metal-organic framework caused by point defects accumulation. Chem. Mater. 2018, 30, 5478-5484. [CrossRef]

41. Zhu, K.; Vukotic, V.N.; O’Keefe, C.A.; Schurko, R.W.; Loeb, S.J. Metal-Organic frameworks with mechanically interlocked pillars: Controlling ring dynamics in the solid-state via a reversible phase change. J. Am. Chem. Soc. 2014, 136, 7403-7409. [CrossRef]

42. Servati-Gargari, M.; Mahmoudi, G.; Batten, S.R.; Stilinović, V.; Butler, D.; Beauvais, L.; Kassel, W.S.; Dougherty, W.G.; VanDerveer, D. Control of interpenetration in two-dimensional metal-organic frameworks by modification of hydrogen bonding capability of the organic bridging subunits. Cryst. Growth Des. 2015, 15, 1336-1343. [CrossRef]

43. Goswami, R.; Mandal, S.C.; Pathak, B.; Neogi, S. Guest-Induced Ultrasensitive detection of multiple toxic organics and $\mathrm{Fe}^{3+}$ Ions in a strategically designed and regenerative smart fluorescent metal-organic framework. ACS Appl. Mater. Interfaces 2019, 11, 9042-9053. [CrossRef] [PubMed]

Sample Availability: Samples of the compounds are not available from the authors.

(C) 2020 by the authors. Licensee MDPI, Basel, Switzerland. This article is an open access article distributed under the terms and conditions of the Creative Commons Attribution (CC BY) license (http://creativecommons.org/licenses/by/4.0/). 